This item was submitted to Loughborough's Research Repository by the author.

Items in Figshare are protected by copyright, with all rights reserved, unless otherwise indicated.

\title{
Low cost current measurement of three phase cables
}

PLEASE CITE THE PUBLISHED VERSION

https://doi.org/10.1109/UPEC.2018.8541910

PUBLISHER

(c) European Union. Published by IEEE

\section{VERSION}

AM (Accepted Manuscript)

\section{PUBLISHER STATEMENT}

Personal use of this material is permitted. Permission from IEEE must be obtained for all other uses, in any current or future media, including reprinting/republishing this material for advertising or promotional purposes, creating new collective works, for resale or redistribution to servers or lists, or reuse of any copyrighted component of this work in other works.

\section{LICENCE}

All Rights Reserved

\section{REPOSITORY RECORD}

Strickland, Matthew, Dani Strickland, Andrew Cross, Brian Goss, Mina Abedi-Varnosfaderani, and Terry West. 2019. "Low Cost Current Measurement of Three Phase Cables". figshare. https://hdl.handle.net/2134/38104. 


\section{Low cost current measurement of three phase cables}

\author{
Matthew Strickland \\ Wolfson School \\ Loughborough University \\ Loughborough, UK \\ matthewstrickland811@gmail.com
}

\author{
Dani Strickland \\ Wolfson School \\ Loughborough University \\ Loughborough, UK \\ d.strickland@lboro.ac.uk
}

\author{
Andrew Cross \\ Wolfson School \\ Loughborough University \\ Loughborough, UK \\ a.cross@lboro.ac.uk
}

\author{
Brian Goss \\ Wolfson School \\ Loughborough University \\ Loughborough, UK \\ b.goss@lboro.ac.uk
}

\author{
Mina Abedi-Varnosfaderani \\ Wolfson School \\ Loughborough University \\ Loughborough, UK \\ m.abedi-varnosfaderan@lboro.ac.uk
}

\author{
Terry West \\ Wolfson School \\ Loughborough University \\ Loughborough, UK \\ t.c.west@lboro.ac.uk
}

\begin{abstract}
Recent growth in embedded generation alongside the anticipated consumer uptake of electric vehicles (EVs) and heat pumps present new challenges for distribution networks. This includes greater fluctuation in electricity demand. Data from existing maximum demand indicators in distribution substations is inadequate to understand the spread of demand over time. Retro-fit datalogging solutions are available for substation monitoring, but cost typically $>£ 1200$, which would be difficult to justify for all distribution substations. This paper looks at the development of a novel low cost alternative designed for measuring load on three phase cables.
\end{abstract}

Keywords - LV monitoring, 3-phase load, power monitoring and control, smart grids

\section{INTRODUCTION}

Distribution Network Operators (DNOs) would benefit from improved visibility of their network in order to optimise planning and operation. This includes the ability to benefit from dynamic ratings, undertake flexible network control and improve planning. Most DNOs have limited monitoring below the $11 \mathrm{kV}$ circuit breakers, so the cost of fitting and operating monitoring devices could be significant. To this end, different DNO's have undertaken separate projects to look at means of implementing low cost monitoring.

Examples, of research in this area include; UK Power Networks (UKPN) "Distribution Network Visibility" [1] Scottish Power Energy Networks (SPEN) "Enhanced substation monitoring project" [2], Northern Power Grid "CLNR Enhanced Network Monitoring" [3] and Western Power Distribution projects [4] - "LV network templates", "LV Sensors" and the "Losses" project.

The UKPN London network is different from most other UK DNO Networks as it has an extensive and widespread monitoring capability, with Remote Terminal Units (RTUs) deployed in approximately $60 \%$ of the distribution substations primarily for the purposes of HV switching. These RTUs had a range of unused features around data captured, which were not being fully utilised. The Distribution Network Visibility LCNF Tier 1 project looked at using the hardware to collect network data. The project then assessed the possibility of manipulating, updating (and where necessary cleansing this data) to automatically detect network performance and issues and produce useful information such as available capacity. Some of the RTU's were upgraded, but the majority were insitu prior to project commencement. Without the benefit of the already installed RTU units. This may not offer a low cost monitoring option.

The SPEN project determined a set of data to be collected at choice substations of; Voltage (1minute interval), Current (10minute interval), Temperature (of selected transformers) and Weather information (at selected sites). To capture the current and voltage, 3-phase current and voltage monitoring devices were used at both primary and secondary substations. The voltage measurement was facilitated using a Drummond bus-bar clamp and the current measurements were reportedly undertaken with Rogowski coils. The typical cost of monitoring quoted by SP Energy Networks is between $£ 1400$ and $£ 2400$ per substation with installation and removal costs of $£ 100$ - $£ 200$. Their conclusions were that a low-cost replacement for the existing MDIs which is permanently fitted with a captured-data communication function would probably give a greater cost/benefit. Should there be less predictable loads or generation which may give rise to the need for more detailed data information, then a more expensive datalogging device could be fitted to measure all the circuit phase loads as necessary. 
The Northern Power Grid project looked at 3-phase monitoring of current and voltage on either $\mathrm{HV}$ or $\mathrm{LV}$ side of a substation (whichever was most convenient). These were monitored at half hourly and 10 minutely intervals as average quantities (for design and control purposes) requested to be $0.5 \%$ accuracy and power quality data where required with changed values sent to control within $15 \mathrm{~s}$ (for control). In terms of quoted costs, these were summarised as: "The cost of the monitoring system, comprising more than 150 monitoring points performing over 3 million measurements per day, was $£ 850 \mathrm{k}$, of which $£ 336 \mathrm{k}$ was the capital cost of the monitoring equipment. It should be noted that the principal use of much of this monitoring equipment was for the purposes of advanced network control. The maximum cost for a secondary substation monitor to provide data for planning purposes, if all secondary substations were to be monitored instead of using smart meter data, is £78. This figure excludes the cost of CTs on the LV Board for the incoming supply (as these will already be fitted), providing that they are sufficiently accurate."

Many commercial organisations offer monitoring solutions including; GridKey [5], Nortech [6], Siemens [7], eMS [8], Sentient [9] and Tollgrade [10] Most of these organisations use traditional sensors with some form of data collection and telemetry solutions. However, costs are still typically higher than around $£ 1000$ per substation.

These projects mostly relied on commercial current and voltage transducers which could be costly to roll out over many substations. The work reported in this paper works on a different principle; that is given a target price of material of $£ 100$ per substation with an additional $£ 50$ installation cost can a substation monitoring product be developed? and what information can it provide? Some attempts at low cost version of traditional transducers have been published including versions of Rogowski coils [11] and current sensors [12-13]. Alternative methods of monitoring loading by inferring values have also been reported. Examples of published work include reports of low cost optical solutions [14] and inferring loading through transformer temperature [15] using low cost stick on devices that allow for communication.

The Rogowski coil can only be used for measuring fields in single core cables, while the designs in ref [12-13] are based on a Rogowski coil but aimed at overhead lines applications. An optical solution is still too expensive and inferring loading through transformer temperature suffers from the need for precalibration and also additional ambient temperature monitoring along with issues of accuracy. The application reported in this paper is novel and allows measurement of the current in a three-core cable from which current loading can be calculated.

Section II looks at the development of theory. Section III introduces the novel hardware to measure the magnetic field and infer the load current. Section IV covers the testing setup of the hardware and Section V and section VI analyses at the results and makes conclusions respectively.

\section{THEORY}

\section{A. Magnetic field measurement}

The magnetic field generated in a 3-phase cable looks very similar to a 2-pole field in a machine. As the current changes in the cable the field appears to rotate as shown in Fig. 1. This time varying change in magnetic field can be detected by a coil and the induced EMF measured. The time-varying dynamic magnetic field around a 3-phase cable was modelled using FEM (finite element modelling).
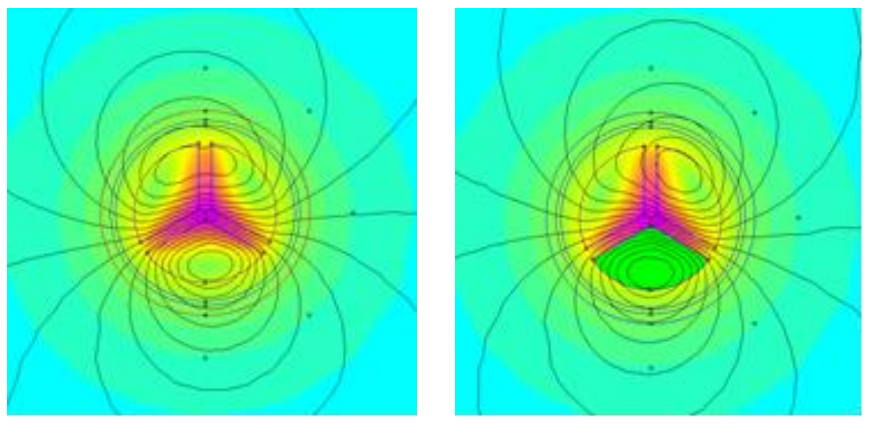

$\mathrm{t}=0.000 \mathrm{~s}$

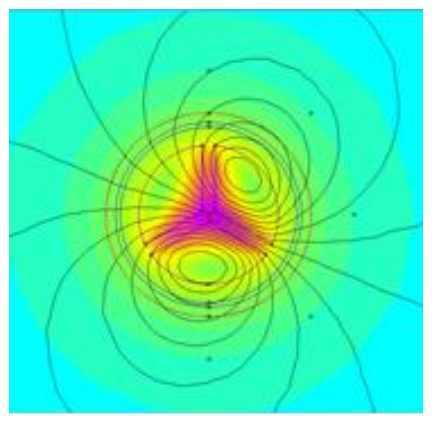

$\mathrm{t}=0.002 \mathrm{~s}$

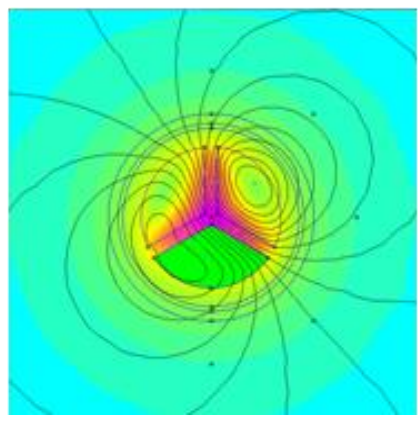

$\mathrm{t}=0.004 \mathrm{~s}$

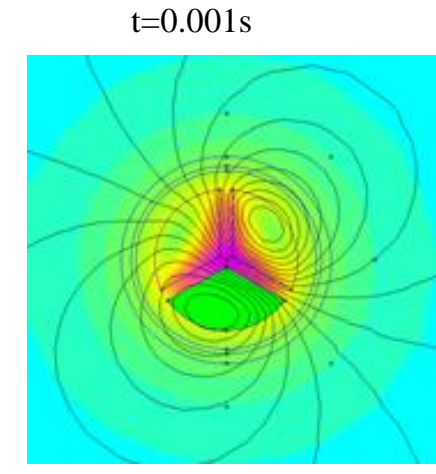

$\mathrm{t}=0.003 \mathrm{~s}$

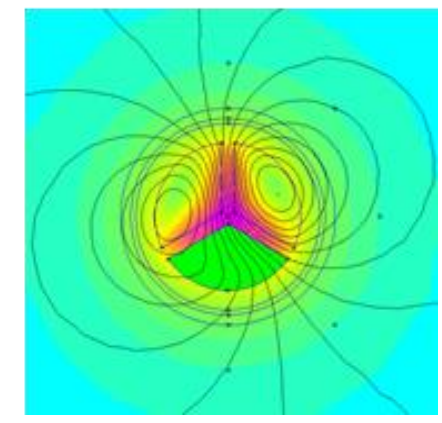

$\mathrm{t}=0.005 \mathrm{~s}$

Fig. 1. Magnetic flux plot showing rotation of magnetic field with time.

Fig. 1 shows a 3 -core $95 \mathrm{~mm}^{2}$ Aluminium conductor, copper screened cable of outside diameter $33.84 \mathrm{~mm}$. It was modelled with 150 A peak current in three phases (R,Y and B) with appropriate $120^{\circ}$ offsets using a finite element model as shown in Fig. 2. The rotating magnetic field has similarities with that in the stator of an induction motor. This time varying magnetic field can be used to induce an EMF in a coil attached to the cable which can then be measured to infer the current. It was decided to design a coil which acts loosely like a locked rotor of an induction machine (but located outside of the 3-core cable) as shown in Fig. 3. 


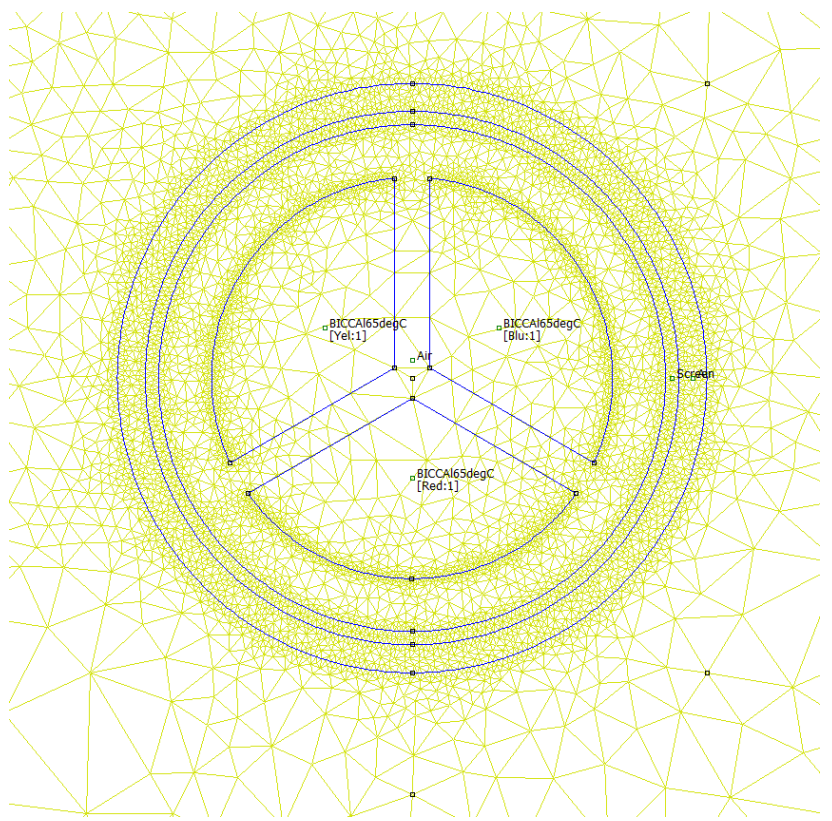

Fig. 2. Model of the three core cable

The coil can be produced by winding enamel wire around a former and then taping the strands together before being fixed to the cable with cable ties linking each corner. This is a low cost and effective means of installation. The coil must be sufficiently rigid to install in this means which is why the thinnest transformer wire was not used. There is an additional design trade-off between the number of turns and the length of the coil. Coiling hundreds of turns similar to a Rogowski coil is time consuming and impacts the radius that the coil is located at.

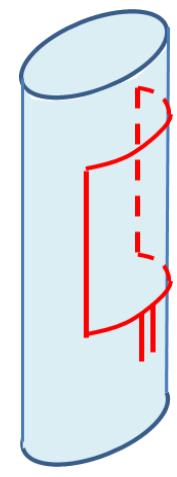

Fig. 3. Coil shape for detecting changing magnetic field

The induced EMF in the coil can be estimated using Faraday's Law (1) where $e$ is the induced voltage [volts], $\mathrm{N}$ is the number of turns in the coil and $\varphi$ is the flux [Wb].

$$
e=-N \frac{d \varphi}{d t}
$$

If it is assumed that the flux density, $\mathrm{B}$ is changing sinusoidally around the conductor as per (2), then the induced EMF in each half of the coil can be calculated from (3) and summed to give a total EMF.

$$
B=\widehat{B} \sin (\omega t+\theta)
$$

Where $\omega=2 \pi f(\mathrm{rad})$.

$$
e=-N \omega r l \hat{B} \cos (\omega t+\theta)
$$

The radius of the cable, $r$ [m] is assumed as the coil is attached to the outside of the cable and 1 is the length of the coil $[\mathrm{m}]$.

Finite element analysis is a useful way of looking at field solutions but can be time consuming to set up and use. A finite element solution could be used to produce values of magnetic field which can then be used in a lookup table to back-calculate loading based on coil induced EMF. However, a more straightforward method is to assume that each current can be represented as a current point source in the centre of the sector (shown by the red dot in Fig. 4 ) and the normal component of magnetic field from each current (the normal field from the "Y" current acting on one half of the coil, e+ , a blue dot, is shown by the green arrow) added to give the total field at each end of the coil. The induced EMF in each half of the coil can be found from (3) and subtracted to give the total coil EMF.

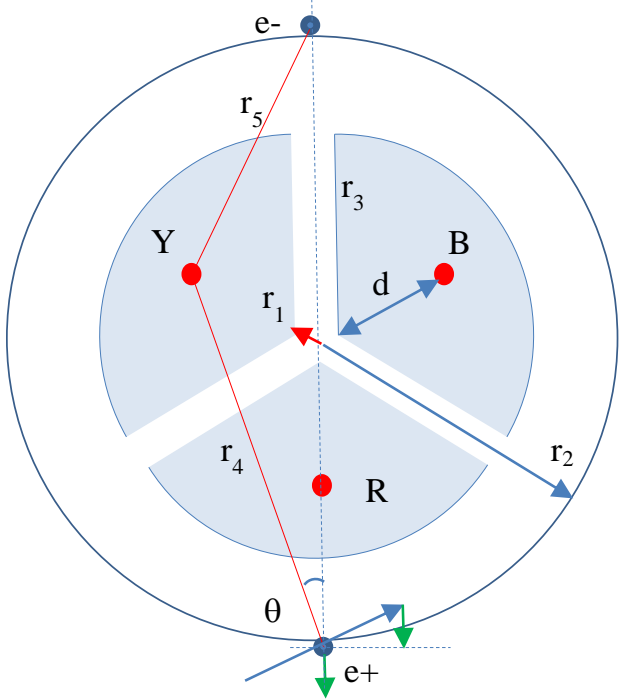

Fig. 4. Simplified model of system

In the approximation if it is assumed that each sector has a half angle $\alpha$ of $60^{\circ}$, then a $95 \mathrm{~mm}^{2}$ cable can be represented by a sector of radius $r_{3}$ of $9.5 \mathrm{~mm}$. The distance from the centre of the sector to the centroid of the sector, $d$, can be found from (4)

$$
d=\frac{2 r_{3} \sin (\alpha)}{3 \alpha}
$$

The distance from the centre of conductor $\mathrm{Y}$ to the coil is then found from (5)

$$
r_{4}=\sqrt{r_{2}^{2}+\left(r_{1}+d\right)^{2}-2 r_{2}\left(r_{1}+d\right) \cos \left(120^{\circ}\right)}
$$

The normal component of the magnetic field, $\mathrm{B}_{\mathrm{n}}$ at the coil $\mathrm{e}+$ due to a current in conductor $\mathrm{Y}, I_{Y}=\hat{I} \sin \left(\omega t-120^{\circ}\right)$ is given by (6) 


$$
B_{n}=\frac{\mu_{o} I_{Y}}{2 \pi r_{4}} \cdot \frac{\left(d+r_{1}\right)}{r_{4}} \sin \left(120^{\circ}\right)
$$

A similar set for the field at e+ due to the current in B and the field at e- due to the currents in $\mathrm{Y}$ and $\mathrm{B}$ can be calculated (the location of the coil as shown with respect to the $\mathrm{R}$ conductor means there is no normal component due to a current in R).

If it is assumed that the currents in all three phases are balanced then the peak induced EMF can be related back to the peak current through (7)

$$
\hat{e}=3 N r_{2}\left(d+r_{1}\right) l f \frac{\mu_{o} \hat{I}}{2}\left(\frac{1}{r_{4}^{2}}+\frac{1}{r_{5}^{2}}\right)
$$

Giving (8)

$$
\hat{I}=\frac{\hat{e}}{3 N f r_{2}\left(d+r_{1}\right) l \mu_{o}\left(\frac{1}{r_{4}{ }^{2}}+\frac{1}{r_{5}{ }^{2}}\right)}
$$

\section{HARDWARE}

To achieve a sufficiently high induced EMF and an acceptable signal to noise ratio (SNR), the coils were designed to be $200 \mathrm{~mm}$ long and have 15 turns. As the magnetic field from the 3 coils rotates like a 2-pole machine, the coil is designed to go $180^{\circ}$ around the cable as shown. Having additional coils offset by $120^{\circ}$ allows the rotating field to be observed in each of the coils. While it is desirable to have this information (and it could give indication of unbalance and also current direction if a reference voltage is present) this is not essential.
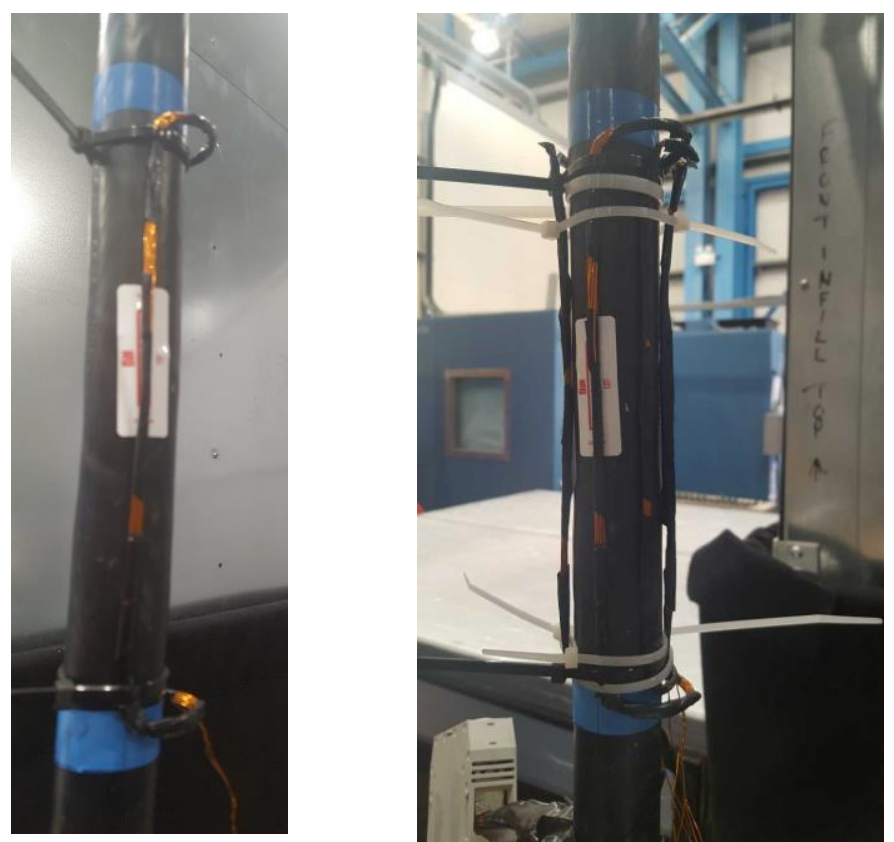

Fig. 5. Photo of a single coil and multiple coils to detect magnetic field

The coils were manufactured on a former from copper transformer wire $(0.5 \mathrm{~mm}$ diameter). The hardware setup is shown in Fig. 5. Using these values in (3) with a peak magnetic field (from the FEM) gives an induced EMF in each coil of approximately $60 \mathrm{mV}$ for a $150 \mathrm{~A}$ peak current.

\section{Other hardware components}

The magnitude of the induced voltage in the measuring coil is a small voltage to measure and this needs to be input into a controller and from there sent over General Packet Radio Service (GPRS) to a server from where it can be retrieved at a later date by the DNO. The signal is magnified using an opamp circuit as shown in Fig. 6. This then passes to a LinkitOne PCB (Arduino compatible) board which has inbuilt GPRS functionality. This allows the measurement to be transferred to a server.

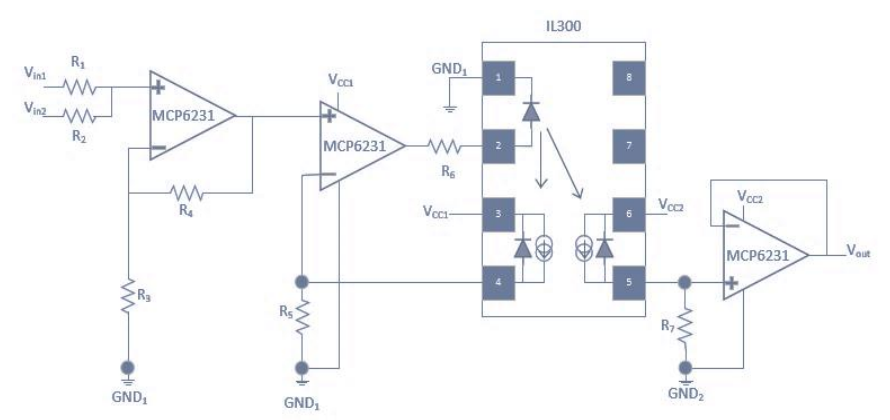

Fig. 6. Level shift and amplifier circuit

\section{A. Costs}

The total cost of the system from coil through to telecoms is given in Table 1. This comes in below the target price of the system.

TABLE I. COST OF HARDWARE

\begin{tabular}{|c|c|c|c|c|}
\hline Vendor & Part & Qty & $\begin{array}{c}\text { Unit } \\
\text { cost }\end{array}$ & $\begin{array}{c}\text { Line } \\
\text { cost }\end{array}$ \\
\hline WS stores* & Transformer wire & $9 \mathrm{~m}$ & $£ 5.00$ & $£ 5.00$ \\
\hline Farnell & IL300 optocoupler & 1 & $£ 1.81$ & $£ 1.81$ \\
\hline Farnell & Green LED & 1 & $£ 0.09$ & $£ 0.09$ \\
\hline Farnell & Terminal Block & 1 & $£ 0.71$ & $£ 0.71$ \\
\hline Farnell & Ceramic Cap 0.1uf & 1 & $£ 0.14$ & $£ 0.14$ \\
\hline Farnell & Trimmer pot 10k & 1 & $£ 1.05$ & $£ 1.05$ \\
\hline Farnell & DIP socket & 1 & $£ 0.37$ & $£ 0.37$ \\
\hline WS technicians* & Bespoke PCB & 1 & $£ 2.00$ & $£ 2.00$ \\
\hline RS & MCP6231T Op Amp & 3 & $£ 0.19$ & $£ 0.57$ \\
\hline Rapid & Power supply & 1 & $£ 4.99$ & $£ 4.99$ \\
\hline Rapid & LinkitOne PCB & 1 & $£ 44.24$ & $£ 44.24$ \\
\hline & & & Total & $£ 60.97$ \\
\hline
\end{tabular}

* Wolfson School of Mechanical Manufacturing and Electrical Engineering, Loughborough University. 


\section{TEST RIG}

\section{A. Test rig}

For initial testing, a hardware equivalent of a substation was setup which recreates many of the characteristics of an LV substation without requiring high voltages to be used.

There are two main aspects of the test facility:

1) A 3-phase, $45 \mathrm{kVA}$ air coiled transformer with variable voltage supply to test vibration and noise based sensors.

2) A high current, low voltage power supply which can supply up to 300 A pk-pk into a shorted 3 phase cable as shown in Fig. 7.

This means that any DNO 1, 2, 3 or 4 core cables can be connected, and the electromagnetic field measured with sensors under test. It could also be used for other tests such as temperature and strain. A Teledyne Lecroy HDO6104 High Definition Oscilloscope was used to validate current sensor measurements:

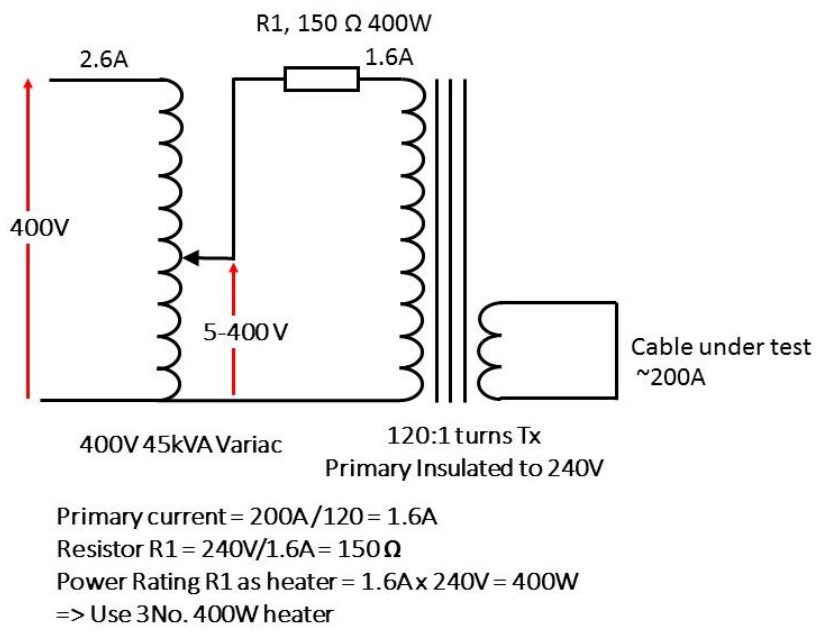

Fig. 7. Simplified 1-line diagram of the test rig.

\section{B. Experimental results}

The current was varied from 0 to $150 \mathrm{~A}$ peak and the induced EMF captured using a LeCroy scope connected to the coil terminals. Fig. 8 shows the waveforms on three coils equidistant around the cable to show the sinusoidal pattern. Fig. 9 shows the variation of EMF in the coil compared to that obtained by theoretical calculation using (7). At high levels of current there is good correlation between expected values and theoretical values. As the current approaches zero the experimental values of EMF become more susceptible to noise and the accuracy tails away.

To help with noise, the output of the coils was amplified and shifted using an op-amp circuit with a gain of 9. Fig. 10 shows the captured waveform at the output of the amplifier circuit. The signal is much clearer and is at a level where it can be fed directly into the LinkitOne board.

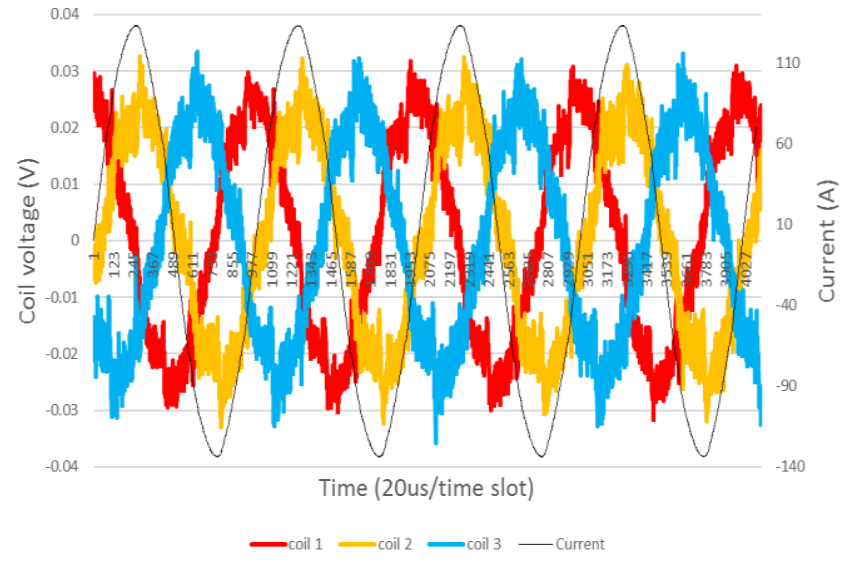

Fig. 8. Measured coil voltage against time at 260A peak-peak load current

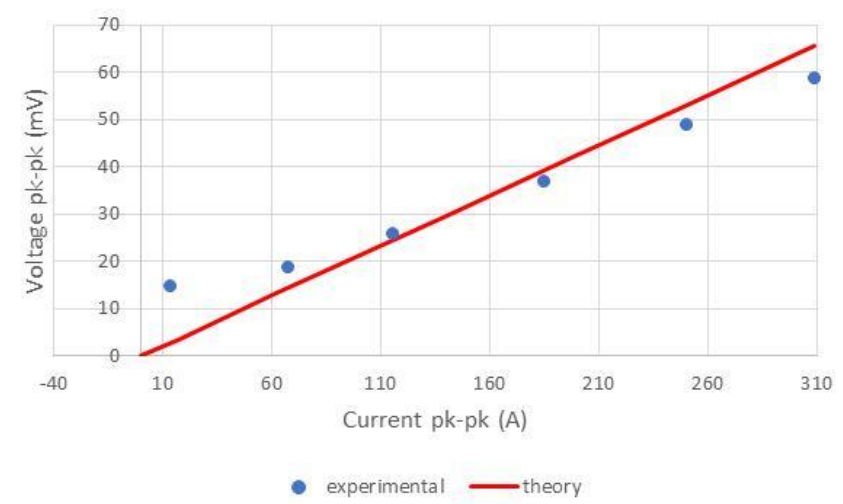

Fig. 9. Voltage at coil terminals for a given current (measured and theoretical)

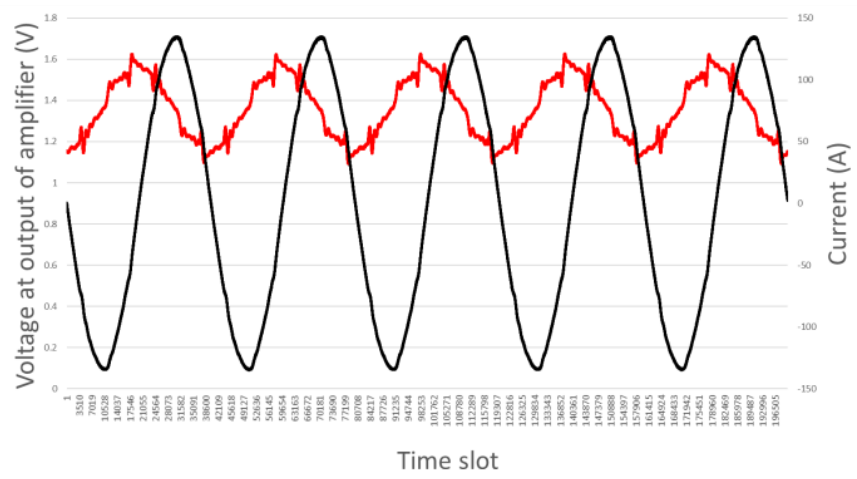

Fig. 10. Measured coil voltage against time at 309A peak-peak load current

The variation of amplifier output with current was recorded and is shown in Fig. 11. The difference between theoretical and experimental values is good with about $2 \%$ accuracy across the range. Difference are due to the spikes in the voltage causing a higher than theoretical value of peak to peak voltage. RMS values show a reverse trend with theory being about $20 \%$ higher than experimental values in Fig. 12. 


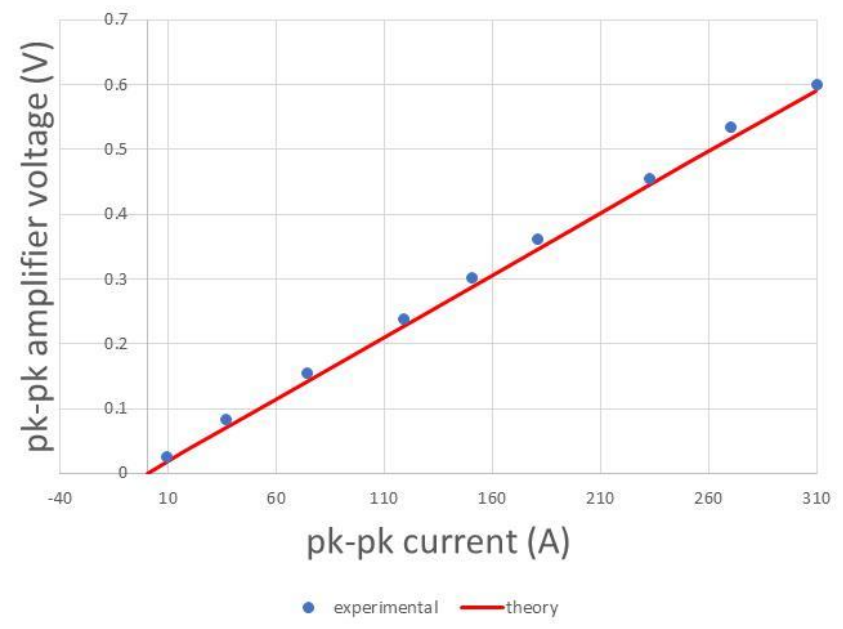

Fig. 11. Voltage at amplifier output (measured and theoretical)

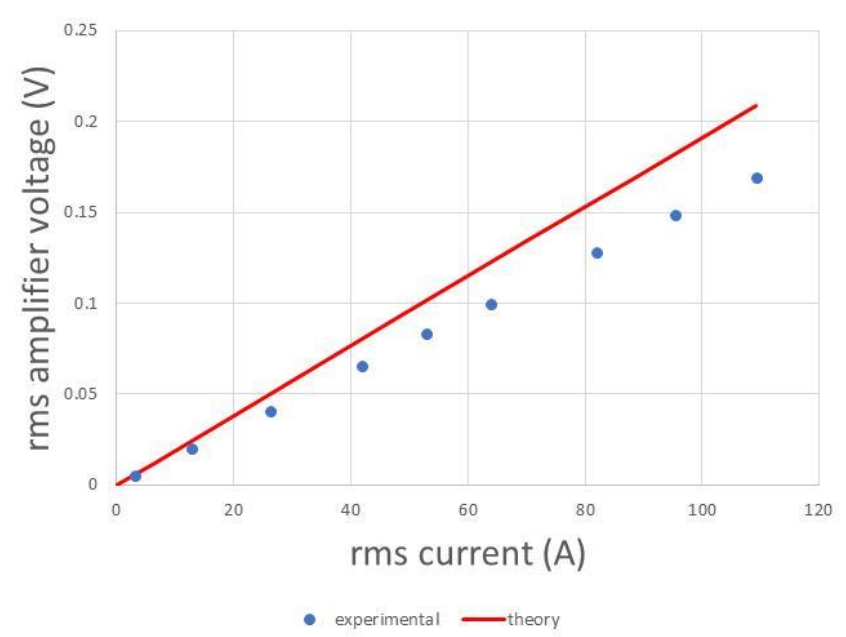

Fig. 12. Voltage at amplifier output (measured and theoretical)

\section{CONCLUSIONS}

This paper investigated the feasibility of using a coil design different from those currently in literature to measure the magnetic field in a 3-phase cable. The design works on the same principle as an induction motor in locked rotor condition but with the "rotor" part located outside of the "stator". For this reason, the measurement technique is referred to as inverted induction measurement (i2m).

The design has been developed as a trade-off between the number of turns (for improved manufacturability) versus length of coil (limited by substation design). There are a number of assumptions inherent in the design of the system, including the presence of a sinusoidal flux density. This is a function of cable geometry and both the flux plots and experimental data shows that it is not exactly sinusoidal.
Under ideal laboratory conditions, there is good correlation between measure and calculated field (A correlation coefficient of 0.999). Whilst finite element analysis has been used to confirm the values, a hand calculation has proved adequate for deducing a formula which allows load current to be inferred to within 10\%. However, there is scope for improvement of this calculation.

There is the potential to have three coils located at regular intervals around the cable which could in theory give an indication of phase imbalance on the cable. The next phase of this project will be to take the coils design forward to trials in a substation environment and check correlation against measured loading data.

\section{ACKNOWLEDGEMENTS}

This work was funded by the Western Power Distribution (WPD) DEDUCE project under the OFGEM Network Innovation Allowance (NIA).

\section{REFERENCES}

[1] UKPN DNV project close down report available at https://innovation.ukpowernetworks.co.uk/innovation/en/Projects/tier-1projects/distribution-network-visibility/Project-

Documents/DNV+CDR+Version+3.0+270214.pdf [accessed April 18]

[2] Available online at https://www.spenergynetworks.co.uk/userfiles/file/EnhancedSubstation MonitoringDeployment07.pdf [accessed April 2018]

[3] Available online at : http://www.networkrevolution.co.uk/wpcontent/uploads/2014/12/CLNR-Enhanced-Network-MonitoringFinal.pdf [accessed April 2018]

[4] Available online at https://www.westernpower.co.uk/innovation [accessed April 2018]

[5] Available online at https://www.gridkey.co.uk/\# [accessed April 2018]

[6] Available online at http://nortechonline.co.uk/applications/lv-substationmonitoring/ [accessed April 2018]

[7] Available online at http://www.siemens.co.uk/pool/energy/uhf_pdm.pdf [accessed April 2018]

[8] Available online at http://www.emsni.com/ [accessed April 2018]

[9] Available online at http://www.sentient-energy.com/products/mm3intelligent-sensor [accessed April 2018]

[10] Available online at http://www.tollgrade.com/smartgrid/smart-gridproducts/smart-grid-mv-sensor/ [accessed April 2018]

[11] Ehsan Abdi-Jalebi, and Richard McMahon," High-Performance LowCost Rogowski Transducers and Accompanying Circuitry", IEEE Trans on Instrumentation and Measurement, Vol. 56, NO. 3, June 2007, 753

[12] Rohit Moghe FrankLambert, and Deepak Divan, "A Novel Low-Cost Smart Current Sensor for Utility Conductors", EEE Trans on smart Grid, Vol. 3, NO. 2, June 2012

[13] Junyong Wu, Zhanfeng Chen, Chen Wang, Liangliang Hao, "A Novel Low-Cost Multicoil-Based Smart Current Sensor for Three-Phase Currents Sensing of Overhead Conductors", Power Delivery IEEE Transactions on, vol. 31, pp. 2443-2452, 2016, ISSN 0885-8977.

[14] Joseba Zubia 1, Luciano Casado , Gotzon Aldabaldetreku , Alfonso Montero , Eneko Zubia and Gaizka Durana "Design and Development of a Low-Cost Optical Current Sensor", Sensors 2013, 13, 13584-13595; doi:10.3390/s131013584

[15] Rohit Moghe and Yi Yang, Frank Lambert, Deepak Divan, "Design of a Low Cost Self Powered "Stick-on" Current and Temperature Wireless Sensor for Utility Assets" 